\title{
Pedagogia Sistêmica: uma Nova Abordagem no Processo de Ensino Aprendizagem
}

\author{
Systemic Pedagogy: a New Approach in the Teaching-Learning Process
}

\author{
Carla Cristina El-Hage Serafim*a; Cleonice Terezinha Fernandes ${ }^{\mathrm{a}}$
}

${ }^{a}$ Universidade de Cuiabá, Programa de Pós-Graduação Stricto Sensu em Ensino. MT, Brasil.

*E-mail: elhageserafim@hotmail.com

\begin{abstract}
Resumo
O século XXI expressa um grande desafio: a educação escolar que não tem conseguido atender a demanda exigida pelas atuais mudanças sociais. A Pedagogia Sistêmica vem ao encontro deste dilema de encontro ao, e não como uma nova metodologia, mas como uma postura do professor: quem ensina é também sujeito que aprende; surgiu enquanto adaptação para a escola-a partir dos trabalhos do filósofo e psicanalista alemão Bert Hellinger, que aborda a visão sistêmica-fenomenológica e os campos morfogenéticos em procedimentos terapêuticos breves. $\mathrm{O}$ objetivo deste estudo é compreender a experiência de professores de CuiabálMT, que colocaram em prática exercícios sistêmicos, a partir de suas próprias narrativas. A metodologia utilizada foi a história oral, estruturada a partir da leitura de artigos e livros de outros professores nacionais e internacionais, que também utilizaram a Pedagogia Sistêmica nos fazeres pedagógicos, realizando uma triangulação com autores consagrados da Educação mundial. Como resultado se traz um percurso histórico da Pedagogia Sistêmica no Brasil e no Mundo; exemplos de atividades escolares com os quais foi possível sentir a importância de revisão de hábitos e posturas frente aos problemas, em sala de aula, quando se coloca a culpa dos baixos resultados somente nos alunos e suas famílias e se esquece de preconceitos e fragilidades pessoais e docentes. A conclusão é de que há ganhos efetivos do professor, durante o processo da auto permissão do olhar sistêmico, em sala de aula, haja vista que esse profissional estará olhando também para suas questões afetivasłemocionais.
\end{abstract}

Palavras-chave: Educação Holística. Práticas Sistêmicas. Ensino-Aprendizagem.

\begin{abstract}
The 21st century expresses a great challenge: school education that has not been able to meet the demand required by current social changes. Systemic Pedagogy is consistent with this dilemma, and not as a new methodology, but as a teacher's posture: the one who teaches is also a subject who learns; it arose as an adaptation to the school from the works of German philosopher and psychoanalyst Bert Hellinger, who approaches the systemic-phenomenological vision and morphogenetic fields in brief therapeutic procedures. The objective of this study is to understand the experience of teachers from CuiabálMT, who put in practice systemic exercises, based on their own narratives. The methodology used was oral history, structured from reading articles and books from other national and international teachers, who also used the Systemic Pedagogy in the pedagogical practice, performing a triangulation with consecrated World Education authors. As a result, there is a historical course of systemic Pedagogy in Brazil and in the world; examples of school activities with which it is possible to feel the importance of reviewing habits and postures in the face of problems, in the classroom, when the blame for the low results is placed only on students and their families and forget personal prejudices and weaknesses and the teachers. The conclusion is that there are effective gains from the teacher, during the self-permission of the systemic perspective process, in the classroom, since this professional will also be looking at his or her emotional affective issues.
\end{abstract}

Keywords: Holistic Education. Systemic Practices. Teaching-learning.

\section{Introdução}

A Pedagogia Sistêmica surgiu a partir dos trabalhos do filósofo, teólogo, psicanalista e professor alemão Bert Hellinger, que traz uma visão sistêmica-fenomenológica ${ }^{1}$
(MERLEAU-PONTY, 1999), e dos campos morfogenéticos ${ }^{2}$ (VIEIRA, J., 2018; HELLINGER, 2001, 2003; SHELDRAKE, 1996, 2004;) para seus procedimentos terapêuticos breves, conhecidos mundialmente, na atualidade, inclusive usado em mediações na Justiça Restaurativa, chamado de Direito

\footnotetext{
1 Fenomenologia é uma corrente filosófica que estuda a consciência e os seus objetos; afirmando a importância dos fenômenos da consciência, os quais devem ser estudados em si mesmos - tudo que se pode saber do Mundo se resume a esses fenômenos, a esses objetos ideais que existem na mente, designados por palavras que representam sua significação na experiência humana. Maurice Merleau-Ponty (1908-1961) o mais importante fenomenólogo francês, sua "Fenomenologia da percepção" (1945) é destaque na Pedagogia Sistêmica.

2 As hipóteses têm sido explicadas pela teoria de evolução dos “campos morfogenéticos” (CMg), formulada pelo biólogo britânico Rupert Sheldrake apoiando-se em conceitos da Física Quântica. Os CMg são campos de forma, padrões, estruturas de ordem. Para Sheldrake (1996), esses organizam os campos de organismos vivos, e cristais e moléculas. A sistêmica utiliza esta ideia de interação "invisível” entre os organismos, sobretudo, aqueles da mesma espécie, saindo do paradigma mecanicistalcartesiano, que explicava quaisquer comportamentos dos seres mediante o estudo de suas partes constituintes e sua posterior redução para leis químicas \físicas; os CMg, ajudam a compreender como os organismos adotam as suas formas e comportamentos característicos.
} 
Sistêmico.

Para grandes pesquisadores da Pedagogia Sistêmica, bem como para as pioneiras Marianne Franke-Gricksch (2009) e Angélica Olvera (2019), por meio da observação de escuta de profissionais da Educação insatisfeitos e desanimados com as dificuldades crescentes em lidar com múltiplas e complexas questões, que envolvem assuntos interpessoais no cotidiano escolar, concluíram que a escola dedica grande parte do seu tempo em organizar a rotina e operacionalizar pontos objetivos relevantes; todavia, por consequência, para as autoras, $\mathrm{o}$ aspecto subjetivo na escola ainda recebe pouca atenção, deixando de contribuir para uma humanização maior nas relações.

Neste cenário, o século XXI expressa um grande desafio: a educação. Esta, no momento, não consegue atender a demanda do Mundo frente às mudanças profundas que vêm ocorrendo na sociedade, principalmente, a tecnológica, a social e a cultural (CORTELLA, 2014). O sistema de ensino e aprendizagem está envolvido em uma série de variáveis, com isso não cabe buscar culpados, mas reconhecer que esses problemas do ensino escolar são resultantes de um fenômeno complexo e que não existem causas únicas e invariáveis. Segundo Celestino (2013), novos conceitos estão sendo questionados a partir de estudos que analisam no ambiente social e familiar as causas dos problemas que interferem no aprendizado do educando. E, nesse sentido, entra o papel do professor como alguém emocionalmente preparado para enfrentar esta demanda, todavia nem sempre é assim.

No início dos anos 1990, pesquisadores (ROSS; ALTMAIER, 1994) afirmaram que os profissionais da educação são expostos a níveis de estresse, que ultrapassam suas habilidades pessoais de autogestão; tais níveis tão elevados são, em geral, provenientes do excesso das demandas no trabalho, agravados por outras variáveis como: suporte profissional reduzido, salas de aulas cheias, indisciplina e agressividade dos alunos e não inclusãolapoio das famílias (ZURLO; PES; COOPER, 2007),cujo motivo será tema da presente argumentação. E parece que relativamente ao momento presente, algo se agravou neste âmbito.

$\mathrm{O}$ fato é que toda sociedade sabe que educar crianças e jovens é de grande responsabilidade e não é uma tarefa fácil, com diversos desafios dados pelo meio social (HECKERT et al., 2001); o que torna a docência uma profissão de risco para a saúde ocupacional perante as elevadas exigências intrínsecas da atividade (OPAS\OMS, 2015).

A Educação Sistêmica mostra como muitas das mediações utilizadas para solucionar os problemas na relação escolaaluno-família falham em função do desconhecimento das ordens inconscientes, que governam o grupo familiar (HELLINGER, 2001). A pedagogia sistêmica é uma nova forma de olhar e explicar o processo educativo, que pressupõe que na aula interagem o professor, os alunos e a escola, representada por suas autoridades e pelo conteúdo acadêmico e aqueles que vêm junto, invisivelmente, que são os progenitores de todos eles (FRANKE-GRICKSCH, 2009).

O professor sistêmico é aquele que sabe da importância de estimular seus alunos para enxergarem suas histórias de vida de maneira generosa, amorosa, grata, com a perspectiva da aprendizagem significativa para a vida. Todos com sua história específica, suas origens, seus antepassados, seus valores e suas normas. A base de todo o trabalho da Pedagogia Sistêmica é o não julgamento, o respeito ao outro, com um olhar de amor ao seu semelhante.

Diante disso, e tendo em vista a importância do panorama atual das relações família-escola, se tem o desafio de realizar novas pesquisas e contribuir para transformar esta relação por meio da valorização dos aspectos positivos relacionados ao processo educativo, porque se vivem novas realidades. Procura-se ao longo deste estudo discorrer acerca dessas possibilidades de mudanças trazidas por essa nova abordagem, no sistema escolar e nas relações educadores-alunos.

Mediante o contexto, o presente manuscrito tem por objetivo principal compreender a experiência de professores e professoras de CuiabálMT, que procuraram colocar em prática exercícios sistêmicos, para amenizar os problemas apresentados em sala de aula, a partir de suas próprias narrativas; articulando com a experiência de outros professores, que também vivenciaram a Pedagogia Sistêmica em âmbito nacional e internacional.

\section{Material e Métodos}

A metodologia utilizada foi a História Oral (THOMPSON, 1992, 2000) de professores e professoras de CuiabálMT, que utilizaram a Pedagogia Sistêmica em seus fazeres pedagógicos, por meio de análise de suas narrativas, levantadas por meio de entrevistas semiestruturadas; bem como de professores e professoras encontrados a partir da leitura de artigos e livros; após foi realizada uma triangulação de dados com autores consagrados da Educação.

A pesquisa teve início com uma revisão bibliográfica clássica, a qual permitiu conhecer esses estudos contemporâneos que abordavam o assunto sobre "Pedagogia Sistêmica" no Brasil e no Mundo. Foram procuradas referências teóricas publicadas com o objetivo de recolher informações sobre os exercícios sistêmicos utilizados por esses professores e professoras e seus resultados e, assim, proporcionar maior entendimento e uma análise bibliográfica pormenorizada, referente aos trabalhos já publicados sobre o tema; por se tratar de um tema novo em Educação.

Os artigos foram selecionadas a partir de buscas nas bases de dados eletrônicos SciELO e Google Acadêmico, livros, trabalhos acadêmicos e periódicos inerentes ao assunto, utilizando-se as palavras-chave: pedagogia sistêmica; exercícios sistêmicos; educação sistêmica; visão sistêmica e abordagem sistêmica.

Teve-se o cuidado de ser seletivo e incluir somente as 
informações mais relevantes, como: os relatos das experiências vividas pelos autores, em que constavam as metodologias aplicadas, os participantes desses exercícios e os resultados.

O mesmo cuidado se teve com a seleção da amostra dos participantes das entrevistas para a composição das narrativas, sob tratamento da História Oral (THOMPSON, 1992; 2000), tendo sido eleitas seis professoras, que vivenciaram a experiência na escola filantrópica Escola Espírita Maria de Nazaré, a partir de uma formação continuada ocorrida em anos anteriores oferecida pela própria escola; cujo parecer ético de autorização da pesquisa pelo CEP consta sob número 3.610.844 de 2019, que se refere aos estudos ligados a um programa de Stricto Sensu em Ensino.

\section{Resultados e Discussão}

A partir do objetivo deste estudo e da análise das pesquisas encontradas, os principais eixos temáticos abordados foram organizados em quatro tópicos inter-relacionados e complementares. O primeiro trata acerca da consciência sistêmica trazida pela Pedagogia Sistêmica e um breve relato da vida de Bert Hellinger, o segundo mostra o percurso da Pedagogia Sistêmica, nascida também na Alemanha e o terceiro relata a chegada dessa nova abordagem ao Brasil, trazendo suas contribuições para o educador no contexto da sala de aula.

Ao longo do texto também será apresentado o quadro resumo dos exercícios sistêmicos encontrados na revisão bibliográfica, seguido daqueles praticados pelas narrativas das professoras participantes do presente estudo.

\subsection{A Pedagogia Hellinger e a ideia de uma consciência sistêmica}

A Pedagogia Sistêmica surgiu a partir do trabalho sistêmico fenomenológico de Bert Hellinger, com base no respeito e no amor à família e tem uma postura voltada aos princípios que, geralmente, são inconscientes e denominadas por ele como Ordens do Amor (HELLINGER, 2003).

A primeira ordem é a do Pertencimento e fala acerca do direito de todos em pertencer ao lugar em que se encontram. A segunda ordem é a da Hierarquia - quem vem primeiro deve ter prioridade sobre quem vem depois, ou seja, nos sistemas familiares, os pais têm prioridades sobre os filhos - os pais são grandes e os filhos pequenos, ou seja, são hierarquicamente precedentes; assim como todos aqueles que nasceram antes, no caso irmãos ou ancestrais. E a terceira ordem é a do Equilíbrio entre dar e receber gerando uma estabilidade que gera um sentimento de justiça, de paz e coesão entre as partes (HELLINGER, 2003).

Anton Suitbert Hellinger, nascido em 1925, em Leimen na Alemanha, morava em Cologne - Itália, sendo parte de uma família católica. Aos 10 anos, foi seminarista em uma ordem Católica. Apesar disso, aos 17 anos se alistou no exército e combateu com os nazistas no front, sendo preso na Bélgica. Aos 20 anos, com o fim da guerra, se tornou padre.
Se formou no curso de Teologia e Filosofia na Universidade de Würzburgo. Foi enviado como missionário católico para a África do Sul, atuou como diretor de várias escolas, como o Francis College, em Marianhill e como pároco local. Atuou, por 16 anos, junto ao povo zulu, sob o regime apartheid (HELLINGER, 2020).

Em 1954, obteve o título de Bacharel de Artes da Universidade da África do Sul e, um ano depois se graduou em Educação Universitária. Ao final dos anos 1960, abandonou o clero e voltou à Alemanha, onde passou a estudar Gestaltterapia. Mudou-se para Vienna para estudar psicanálise. Bert Hellinger se entregou ao estudo profundo da Filosofia, da Pedagogia, da Teologia, na cultura zulu e nas teorias e métodos terapêuticos para construir esta ciência, que culminou com a construção de uma riqueza própria em sua forma de trabalhar, trançando os conhecimentos concebidos por vários autores. Seus pensamentos estão em mais de 100 livros, dos quais na maioria não é o autor; sua bibliografia foi traduzida em mais de 27 idiomas (GARCIA, 2019).

Bert Hellinger era leal à própria alma e percepção, com o enfrentamento às autoridades alheias, o permitiu ultrapassar discursos, crenças e limitações, para observar os fenômenos como são. Por seu trabalho com as Constelações Familiares, Bert Hellinger recebeu reconhecimento mundial, quando foi indicado ao Prêmio Nobel da Paz em 2011 (CUDEC, 2019). As Constelações familiares, inicialmente, eram voltadas para as questões familiares e sua aplicação basicamente terapêutica. Bert Hellinger aprofundou seus estudos e as Constelações se expandiram do campo familiar para o educacional, o organizacional, da justiça - sendo hoje usada em mediações e resoluções de conflitos, denominado Direito Sistêmico, da saúde, entre outros.

Atualmente, a Constelação Familiar é reconhecida como uma ciência, chamada de Hellinger Sciencia, na qual por meio de uma abordagem sistêmica e fenomenológica, compreende cada sujeito como pertencente a um grande sistema, no qual existe um processo de compensação de leis naturais, que influenciam a vida e decisão de todos os membros desse sistema (GARCIA, 2019; MELLO, 2018; HELLINGER, 2001). Ao longo de seu trabalho, Hellinger sintetizou as três ordens naturais acima citadas - pertencimento, hierarquia e equilíbrio, que fazem com que todo o sistema se mantenha em perfeita harmonia e equilíbrio, desde que respeitadas (HELLINGER, 2003).

Bert Hellinger enfatiza a importância da relação entre pais e professores seguir a ordem sistêmica, na qual primeiro vem os pais, hierarquicamente superiores, logo após os professores e, depois, as crianças. Para ele, o professor precisa se apropriar de conhecimentos sistêmicos para perceber seu real lugar e sua função na escola, favorecendo, assim, uma melhor relação família-escola. O professor é apenas professor e deve perceber a importância de estar em paz, em harmonia, com sua própria família de origem. Acolher seus pais no coração, entendendo que não é melhor que seus pais, nem que seus 
alunos e se libertar seguindo em frente e dando continuidade para sua história de vida.

Para se ilustrar mais acerca da influência inconsciente do educador e seu estado emocional - e de seu campo morfogenético já mencionado - em sala de aula e, também, influenciado pelo campo dos alunos, reciprocamente, em uma via de mão dupla, vale citar uma pesquisa realizada em 36 escolas, situadas em bairros de Nova York, considerados menos favorecidos socioeconomicamente, cujo objetivo era melhorar a qualidade das relações nas classes de 224 professores, ao estimular a sua competência social e emocional. Os participantes eram regentes do $5^{\circ}$ ano do Ensino Fundamental e foram submetidos ao programa CARE for Teachers (Cultivating Awareness and Resilience in Education), cujos instrumentos eram: exercícios de habilidades emocionais, redução de estresse e práticas de mindfulness ${ }^{3}$ - respiração com consciência plena, caminhada consciente, escuta atenta e práticas de compaixão e de autocuidado. Os resultados impressionaram, porque os professores participantes relataram maior poder de regulação de suas emoções; diminuição de suas aflições\conflitos psicológicos; maior habilidade〉gosto ao ensinar e mais atenção consciente, ou seja, menos dispersão do momento presente - do aqui e do agora.

No entanto, o que se quer salientar neste relato acima e fato que realmente surpreendeu os pesquisadores foi que também se observou um aumento na organização da sala de aula e no próprio estado emocional dos estudantes e em sua concentração nas atividades (JENNINGS, 2018). Isto os estudiosos da Pedagogia Sistêmica e da CNV - Comunicação Não-Violenta ${ }^{4}$ (ROSEMBERG, 2019) afirmam: o campo de influência psíquicalemocional vai além do visível; muito embora estes autores não utilizem o termo campo morfogenético de Sheldrake (2004; 1996). Pedagogia Sistêmica e CNV são campos que se afinam completamente e cuja conexão será aprofundada na dissertação base deste manuscrito.

\subsection{O percurso da Pedagogia Sistêmica - da Alemanha para o Mundo}

Os estudos realizados na atualidade apontam para a necessidade de olhar a sala de aula como espaço de interação de grande importância entre os sistemas educacional, familiar e social. A Pedagogia Sistêmica é um novo paradigma que vem ampliando essa visão do que pode existir de fato por detrás das dificuldades de aprendizagem, que é o movimento do ser humano para a vida, para conquistar seus espaços. Essa abordagem sistêmica não substitui nada da pedagogia própria de cada escola e de cada professor, essa respeita e agrega o trabalho, entende a força de cada metodologia e leva o educador a ter uma nova postura (FONSECA, 2018).

Essa nova postura abre espaço para uma reflexão, que se manifesta no contexto educativo, e resulta na necessidade de se observar os princípios que sustentam as Ordens do Amor (HELLINGER, 2001, 2003), para que sirvam de um norte para a convivência escolar, ao respeitarem quem veio hierarquicamente antes e depois; o vínculo entre as gerações tanto para os professores e professoras como para os alunos; a importância de respeitar o lugar ocupado por cada um, ou seja, quem e como é o pai, a mãe, o professor, a professora, e todos os envolvidos na gestão escolar (VIEIRA, 2014). Diversas escolas, em todo o Mundo, experimentam e apresentam relatos impressionantes sobre as transformações que ocorrem com alunos, professores e escolas com a aplicação da Pedagogia Sistêmica.

Esse novo paradigma vem sendo desenvolvido em vários países como México, Alemanha e Espanha (MELLO, 2018) e alguns Estados brasileiros como Mato Grosso, Mato Grosso do Sul, São Paulo e no Distrito Federal (FONSECA, 2018; VIEIRA, J., 2018; GUEDES, 2012) ampliando a visão significativa do todo na relação escola-família. Com isso, surge a possibilidade de se criar, a partir da escola, um ambiente de inclusão, em que todos possam assumir os seus papéis, levando em conta os sistemas familiares, educativos e institucionais e, dessa maneira, fazer com que cada um e suas ações sejam entendidos por completo, ajudando o sujeito a construir o próprio autoconhecimento, entregando o melhor de si.

Marianne Franke-Gricksh, terapeuta, pedagoga, professora, durante 25 anos lecionou em escolas de primeiro e segundo graus na Alemanha. Uma das maiores especialistas em Pedagogia Sistêmica do Mundo, com formação em terapia familiar, a sua experiência é expoente na área. Foi dela um dos primeiros movimentos na aplicação do conhecimento sistêmico-fenomenológico de Bert Hellinger dentro da escola. A sua experiência e os resultados que ela observou moldaram o movimento que veio a se tornar a Pedagogia Sistêmica mundialmente conhecida (MELLO, 2018; FRANKEGRICKSCH, 2009).

3 O termo atenção plena (Mindfulness, em inglês; Sati em Pali - idioma hindu; e consciência plena em Português) se refere a um estado mental, que se caracteriza pela autorregulação da atenção para a experiência presente, em uma atitude aberta, curiosa, ampla e tolerante, dirigida a todos os fenômenos que se manifestam na mente consciente: pensamentos, fantasias, recordações, sensações e emoções percebidas no campo de atenção são aceitas como são. Criada pelo professor Jon Kabat-Zinn (2005), norte-americano, inspirada nas tradições budistas desde 2.600 anos atrás, da qual foi retirado o caráter religioso. Para Kabat-Zinn (2005), mindfulness está relacionado a "estar em contato" com um profundo questionamento sobre a sua visão de mundo e sobre quem você efetivamente é.

4 CNV- Criada por Marshall Bertram Rosenberg (2019) psicólogo americano, compreende as habilidades de falar e ouvir, que leva as pessoas a se entregarem ao momento, sem reservas, possibilitando a conexão com si mesmos e com os outros, permitindo assim que a compaixão se desenvolva. Quanto à expressão Não-Violenta, ele faz uso da definição de Gandhi, se referindo a uma condição compassiva natural que aparece quando a violência é afastada. Ele propõe que com a CNV, as respostas aos estímulos comunicacionais deixem de ser automáticas e repetitivas e passem a ser mais conscientes e baseadas em percepções do momento. 
Marianne Franke-Gricksch (2009) relata, em seu livro, "Você é um de Nós", que sempre foi defensora da inclusão da família na dinâmica escolar, de modo a reconhecer que a hierarquia entre pais e filhos é a única que existe naturalmente. Assim, professores e alunos devem colaborar lado a lado. Porém, como muitos professores e professoras, em alguns momentos se sentiam solitários, em suas tarefas pedagógicas, e cada vez mais limitados pelas condições existentes da profissão e com angústias e frustrações laborais, desenvolveuse interesse pelas terapias familiares, momento em que conheceu Bert Hellinger.

No início tratava a sua área de trabalho e a nova área de conhecimento de forma distinta, porém depois de algum tempo, as experiências sistêmicas surgiram de uma forma natural e espontânea, em sua sala de aula; Marianne conseguiu transferir muitas compreensões e procedimentos da terapia sistêmica familiar para o âmbito pedagógico geral da escola.

Sobre isso, Cury (2017) propõe que o professor não dever ser um personagem, em sala de aula, um ator que só comunica a sua matéria. Deve se colocar no processo, falar, o tanto quanto possível, de algumas de suas experiências, crises, perdas e frustrações, conquistas, pelas quais passou. Essa técnica produz Janelas $L i g h t^{5}$ inesquecíveis, criando pontes inabaláveis entre professores e alunos. Sobre esta ideia também Paulo Freire já falava desde os idos dos anos 1960, em seus círculos de cultura (FREIRE, 1987); quebrando a verticalidade autoritária da sala de aula. No entanto, aqui se insere a preocupação também com a saúde emocional do professor - aquele que será o maestro da orquestra.

A respeito disso, o MEC (BRASIL, 2016) realizou uma ampla pesquisa sobre a saúde dos professores com base nos dados do Censo Escolar de 2014, envolvendo 6.510 professores de 5.737 escolas em todo o país. Foram constatados diversos indicadores alarmantes: $64 \%$ dos entrevistados enfrentam ruídos intensos no decorrer da atividade laboral; 29,7\% sofrem de violência verbal por parte dos alunos; e 56,2\% excedem o limite recomendado de 40 para mais horas de trabalho semanais. Os dados sobre qualidade da gestão escolar são também alarmantes: 40,6\% mencionaram não terem apoio social na escola; $14,9 \%$ consideram não terem autonomia no ambiente escolar; e 50\% têm dificuldade para faltar ao trabalho, mesmo que em situação desfavorável de saúde.

Os professores estão expostos a fortes demandas emocionais, físicas e ocupacionais geradoras de estresse crônico, porque estas ocorrem diária e ininterruptamente, podendo ainda se agravar ao longo do tempo, levando ao estresse ocupacional, que ocorre pela relação entre características pessoais, de maior ou menor vulnerabilidade às condições, dado por exemplo à epigenética, associado às (não boas) condições de trabalho. Dessa forma, as exigências laborais criadas ultrapassam a capacidade de enfrentamento do professor, que se vê cada vez mais pressionado e acuado (GOMES; PEREIRA, 2008). Na área laboral da educação, esse fato tem chamado a atenção pelo crescimento de doenças como: irritação, ansiedade, obesidade e até o caso mais grave de depressão, entre outras (PIOLLI; HELOANI; SILVA, 2013).

Em consequência desse quadro atual, muitos professores são acometidos pela Síndrome de Burnout - severo quadro emocional decorrente do acúmulo excessivo de estresse em trabalhadores, cuja profissão é muito competitiva e apresenta demasiada responsabilidade, como médicos, bombeiros, enfermeiros, bancários, sendo que estas são as principais, segundo a OMS, nas quais estão incluídos os professores.

Burnout (combustão total em tradução nossa) transforma o trabalho em um sacrifício diuturno que traz nervosismo, sofrimento psicológico, e problemas físicos como cansaço demasiado e inexplicável e tonturas (FRAZÃO, 2018). A síndrome foi incluída, em 2019, na Classificação Internacional de Doenças da Organização Mundial de Saúde - OMS. A nova classificação, chamada CIP-11, foi aprovada durante a $72^{a}$ Assembleia Mundial da OMS e entrará em vigor no dia 1 de janeiro de 2022 (OMS, 2019). Neste âmbito se insere o professor como alguém que terá também mais qualidade de vida ao adentrar na Pedagogia Sistêmica, cuidando de si e de seus alunos de forma amorosa, compassiva e respeitosa.

Mediante este quadro, que é mundial, Franke-Gricksch (2009) explica que gradualmente conseguiu ver nas crianças os representantes de suas famílias com suas normas, suas dinâmicas próprias e suas tarefas particulares. E se acrescenta que certamente o professor também se verá neste lugar, e se pode afirmar baseado em vivência pessoal com a referida Pedagogia. Marianne iniciou o trabalho em seu ambiente escolar denominando-o "jogo familiar", com base no pensamento de Bert Hellinger. Uma das dinâmicas foi que em uma de suas aulas, inesperadamente, disse aos seus alunos: "Eu sempre vejo vocês juntos com seus pais em nossa sala de aula. Para mim está claro que aqui não estão sentados apenas 22 alunos, mas 22 famílias perante mim, portanto junto com pai e mãe são 66 pessoas..." (FRANKE-GRICKSCH, 2009, p. 22).

No dia seguinte, foi sugerido que cada aluno levasse uma foto sua junto com seus pais para serem colocadas na sala. Outras ideias surgiram e para a autora as crianças ficaram muito mais tranquilas quando foram lembradas da presença e o apoio dos pais em suas vidas, para ela, isso tudo não tem nada

\footnotetext{
5 A Inteligência Multifocal é uma área da Psicologia que estuda o QI de maneira diferente, dando códigos de inteligência na área comportamental e sentimental do cérebro. Cury (2017) explica que as janelas killer (assassina - tradução nossa) é uma zona de conflitos (no córtex cerebral), em que se arquivam as experiências ruins, traumas, tristeza, medo, baixo autoestima, timidez, entre outros. Quando uma dessas janelas está aberta, essa bloqueia a inteligência, a lucidez, o raciocínio esquemático, a serenidade e a sabedoria. As Janelas Light (luz -tradução nossa) arquivam as boas experiências e agem de maneira inversa a killer.
} 
a ver com terapia, mas com uma visão de mundo (FRANKEGRICKSCH, 2013). Surge, então, um novo olhar dentro do sistema educativo, que se encontra inter-relacionado ao sistema familiar, "ficou claro para mim que havia construído em minhas aulas uma boa ponte para as crianças entre o lar e a escola".

As Constelações familiares me conduziram a uma nova compreensão dos alunos. Vi como estão inseridos em suas famílias e sua lealdade a elas. Mas também reconheci as forças que empregavam constantemente para ligar sua vida familiar à escolar e percebi que essas forças poderiam ser frutíferas. $\mathrm{Na}$ verdade, isso acontece quando nós, professores, abrimos nosso coração às famílias, permitindo-lhes entrar em nossas salas de aula como uma presença invisível e permanente (FRANKE-GRICKSCH, 2009, p. 21).

Nestes relatos empolgantes sobre as experiências, a autora descreve, partindo da sua visão de professora e terapeuta experiente, como as ideias sistêmicas possibilitam basicamente um novo e eficiente aprendizado e fomentam um trabalho conjunto e criativo de alunos, professores e pais. É importante observar que esta proposta se caracteriza como uma mudança de atitude, de postura do professor, revelada em um movimento interno e externo de profundo respeito aos pais e familiares de cada criança ou adolescente, e também de aceitação, sem julgamento, das ações e das condições de vida dessa família. A Educação Sistêmica vem ao encontro da necessidade de gerar e fortalecer o vínculo entre os professores e os alunos, incluindo o sistema familiar de origem dos mesmos, promovendo a aprendizagem de maneira conjunta escola e família (GARCIA, 2019; FONSECA, 2018; MELLO, 2018; FRANKE-GRICKSCH, 2009).

Depois disso, a abordagem se difundiu pelos países de Língua Espanhola, especialmente o México e a Espanha, através da mexicana Angélica Patrícia Olvera Garcia, professora e diretora da primeira Universidade Hellingeriana. Com mais de 47 anos de experiências, é a criadora da pedagogia sistêmica com enfoque em Bert Hellinger aplicada a educação em âmbito internacional (Alemanha, Espanha, México) e mais recentemente no Brasil (MELLO, 2018).

\subsection{A Pedagogia Sistêmica chega ao Brasil}

Compreender os movimentos que ocorrem na relação entre professores, alunos, escolas e famílias é a proposta dessa nova pedagogia (GARCIA, 2019). A Pedagogia Sistêmica tem mostrado com muita clareza que, quando o sistema de ensino permite, reconhece e valoriza a presença do sistema familiar da criança no dia a dia escolar, uma nova possibilidade de educação e desenvolvimento surge no aluno, com resultados poderosos e surpreendentes (ANDRADE, 2018; VIEIRA, J., 2018; GUEDES, 2012). Com isso, algumas escolas no Brasil estão adotando essa nova abordagem como se pode confirmar em vários relatos de professores já existentes na literatura e em artigos científicos. No presente manuscrito foram incluídos alguns depoimentos de professores, que utilizaram os exercícios sistêmicos em suas salas de aula, conforme os Quadros 1 e 2 .

Quadro 1 - Sinopse dos exercícios sistêmicos aplicados por professores em sala de aula - dos artigos elencados neste estudo

\begin{tabular}{|c|c|c|c|}
\hline Autor & Exercícios Sistêmicos & Participantes & Resultado \\
\hline $\begin{array}{l}\text { Pereira } \\
(2013)\end{array}$ & $\begin{array}{l}\text { - Círculo de conversa (Inclusão paterna); } \\
\text { - Ouvindo o coração; } \\
\text { - Gratidão e reverência aos pais. }\end{array}$ & $\begin{array}{c}\text { Crianças e } \\
\text { Adolescentes. }\end{array}$ & $\begin{array}{l}\text { - Diminuição de alienação parental; } \\
\text { - Melhoria nos relacionamentos entre os } \\
\text { alunos. }\end{array}$ \\
\hline $\begin{array}{l}\text { Fonseca } \\
(2013)\end{array}$ & $\begin{array}{l}\text { - Círculo de inclusão; } \\
\text { - Bonecos de força dos pais; } \\
\text { - Eu vejo você! } \\
\text {-Dando um lugar no coração da professora } \\
\text { para os pais; } \\
\text { - Misturinha das células. }\end{array}$ & Alunos do $4^{\circ}$ ano & $\begin{array}{l}\text { - Abertura das crianças para relatarem seus } \\
\text { sentimentos; } \\
\text { - Participação mais ativa dos pais na escola. }\end{array}$ \\
\hline $\begin{array}{l}\text { Mello } \\
(2018)\end{array}$ & $\begin{array}{l}\text { - Fio invisível do coração; } \\
\text { - Mural com fotos dos pais; } \\
\text { - Inclusão do pai falecido; } \\
\text { - Misturinha das células. }\end{array}$ & $\begin{array}{l}1^{\circ} \text { ano do ensino } \\
\text { fundamental }\end{array}$ & $\begin{array}{l}\text { - Melhor comportamento em casa e na sala de } \\
\text { aula; } \\
\text { - Aluno mais tranquilo e seguro. }\end{array}$ \\
\hline $\begin{array}{l}\text { Sivek } \\
(2015)\end{array}$ & - Você faz parte! & Ensino Médio & $\begin{array}{l}\text { - Abertura para relatarem suas dificuldades } \\
\text { emocionais e de relacionamentos; } \\
\text { - Melhor inclusão entre os alunos. }\end{array}$ \\
\hline $\begin{array}{l}\text { Garlet } \\
(2015)\end{array}$ & $\begin{array}{l}\text { - Abraço coletivo de pertencimento; } \\
\text { - Você é um de nós; } \\
\text { - Meditações para sentirem a presença dos pais }\end{array}$ & Ensino fundamental & $\begin{array}{l}\text { - Alunos mais concentrados; } \\
\text { - Aumento na realização de tarefas; } \\
\text { - Menos rebeldia; } \\
\text { - Aumento e aprovações no final letivo. } \\
\text { - Melhor colaboração entre a turma. }\end{array}$ \\
\hline
\end{tabular}

Fonte: Dados da pesquisa. 
Quadro 2 - Súmula das narrativas das seis professoras adeptas da Pedagogia Sistêmica em CuiabálMT

\begin{tabular}{|c|c|}
\hline Perguntas & Ial seu conceito de inclusão familiar na escola e como você vê esse processo acontecer na escola? \\
\hline Respostas & 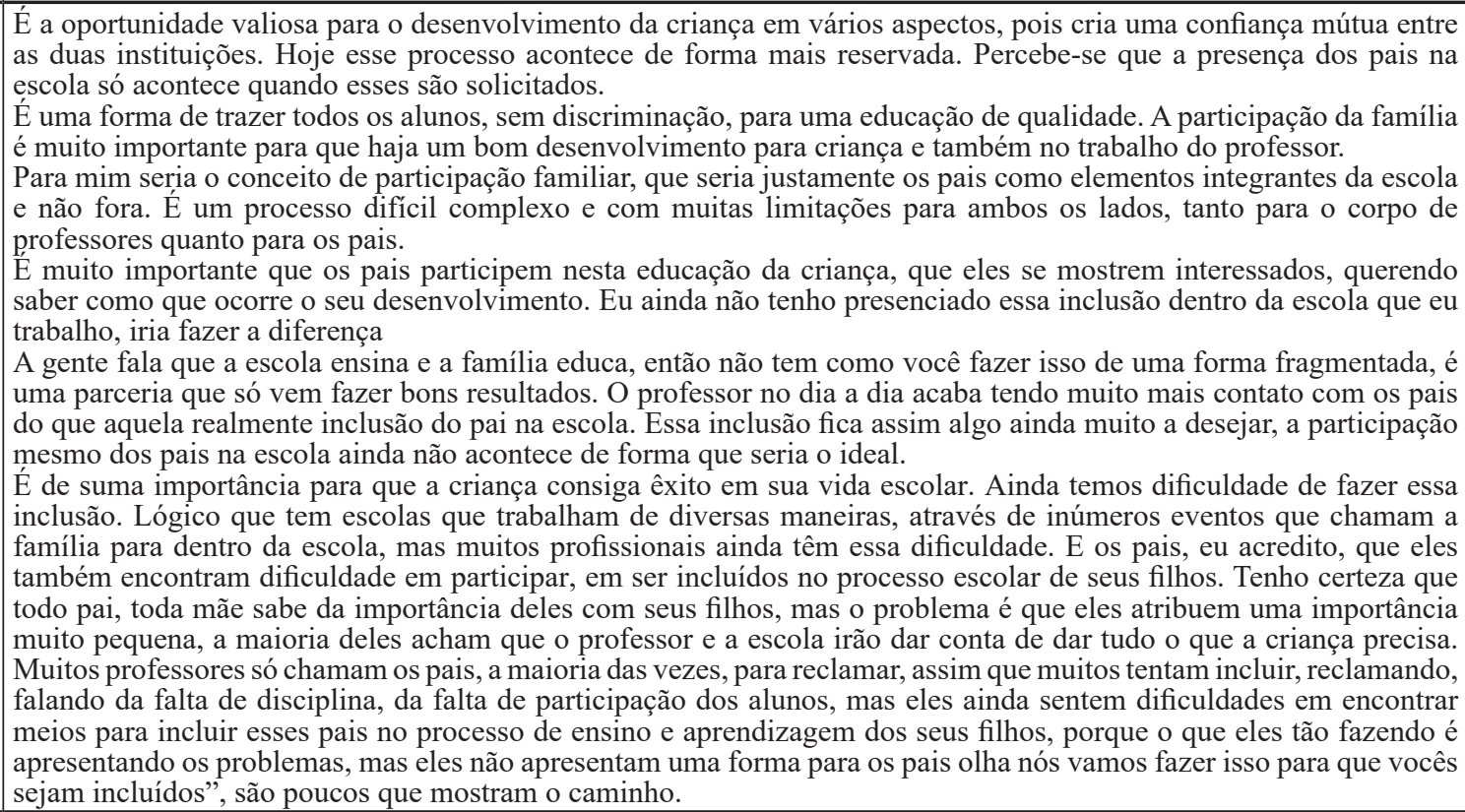 \\
\hline$\overline{\text { Per }}$ & Na sua concepção de educador (a) o que os seus alunos trazem para a sala de aula? \\
\hline Respostas & $\begin{array}{l}\text { Os alunos trazem para dentro da sala de aula vivencias do seu cotidiano, em formas de brincadeiras, em forma de } \\
\text { linguagem ou em forma de abordagem ao outro. Se torna necessário muita cautela, como professora, em chamar a } \\
\text { atenção da criança para não enfatizar mais ainda aquilo que precisa ser contornado } \\
\text { As criançá trazem suas manias, falta de comportamento, birra, falta de limite e algumas crianças com vocabulário que } \\
\text { nem é próprio para sua faixa etária e aí nós temos que saber é lidar com essa situação, sem machucar ou ofender ou } \\
\text { constranger a criança, mas trazendo ela ali para perto da gente, conversando com carinho, respeitando mesmo aquela } \\
\text { criança, até mesmo porque a gente não sabe qual que é o dia a dia dessa criança, qual é o ambiente que ela vive para } \\
\text { ela ser daquela forma. Então, a gente tem que ver tudo isso, até mesmo para poder ajudar essa criança. } \\
\text { Eu diria que eles trazem para mim experiências muito mais amplas que eu poderia esperar, isso em todos os Campos. } \\
\text { Todos os tipos de conhecimento, de atos, de costumes, com certeza uma bagagem enorme já sabe muitas coisas sobre a } \\
\text { vivência que eles têm em casa com os adultos que eles convivem. Tem o que eles veem na televisão, eles com certeza } \\
\text { trazem bastante coisa consigo. } \\
\text { As crianças trazem muitas coisas, muitos conhecimentos das suas casas para nossa sala de aula. } \\
\text { A gente sabe que a família é o ponto fundamental para ensinar todos os valores e a escola tem o dever de dar continuidade } \\
\text { de passar o conhecimento científico, então eles deveriam trazer esses valores, só que devido à falta de ensinamentos } \\
\text { fundamentais que os pais não repassaram, isso não acontece. Nós recebemos crianças indisciplinadas, agressivas, } \\
\text { desatentas, desobedientes, irresponsáveis, além de que recebemos crianças sem tomar banho, sem escovar os dentes } \\
\text { porque em casa não é cobrado, nós temos crianças que vem todos os dias para sala de aula sem tarefas prontas, porque } \\
\text { não é cobrado em casa, temos crianças mentirosas, causadores de intrigas, porque isso é feito por ele no seu cotidiano } \\
\text { e não é corrigido pelos seus pais }\end{array}$ \\
\hline & ual o seu lugar na sala de aula? Como você se sente nesse lugar? \\
\hline Respostas & 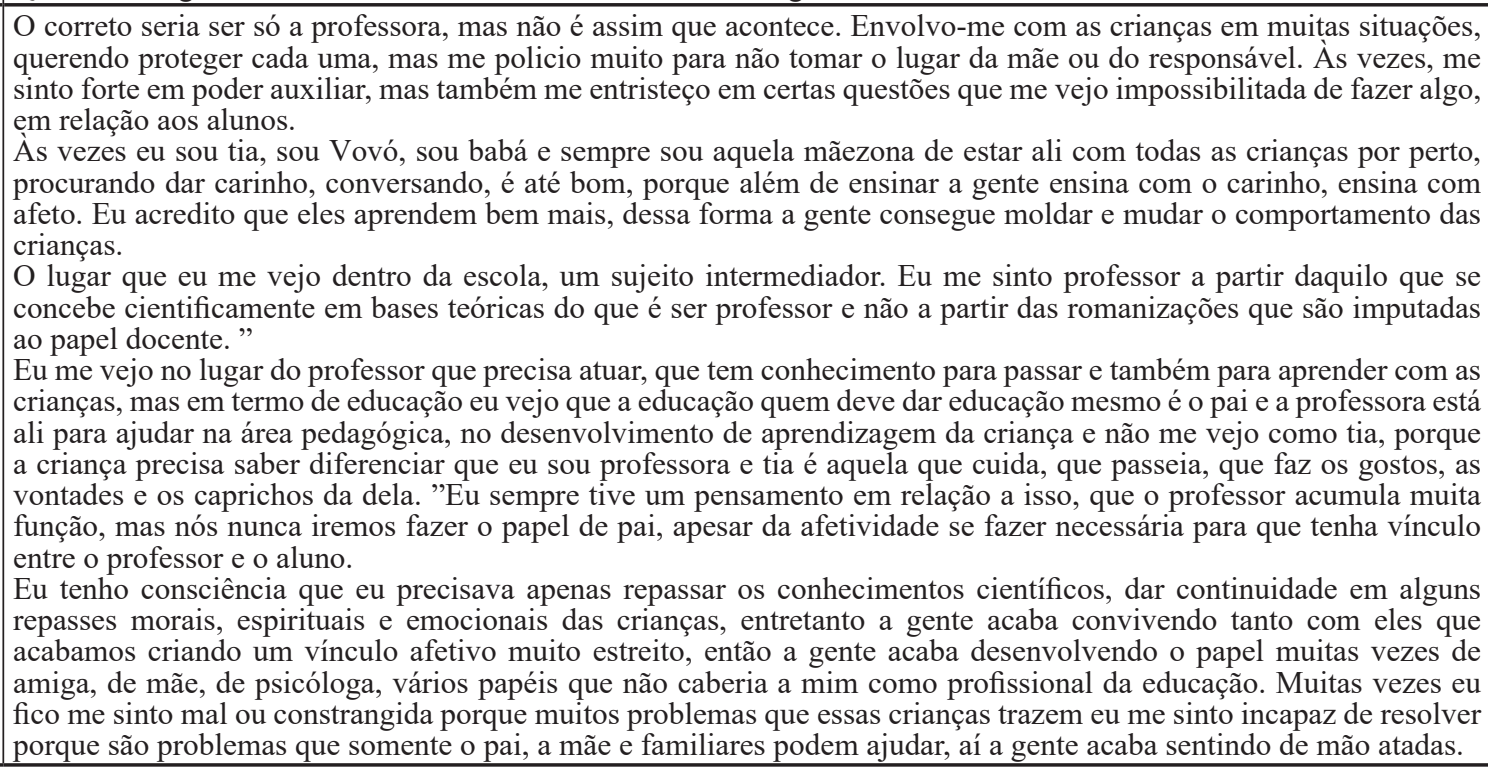 \\
\hline
\end{tabular}




\begin{tabular}{|l|l|}
\hline Pergunta & Qual a importância que os pais dos seus alunos têm para você (no cotidiano escolarına dinâmica da sala de aula)? \\
\hline \multirow{5}{*}{ Respostas } & $\begin{array}{l}\text { Acredito que quando trabalhamos com dedicação com as crianças, na construção do conhecimento e da interação dos } \\
\text { mesmos dentro do contexto escolar, os pais fazem parte desta etapa e podem colaborar muito na compreensão de como } \\
\text { estamos trabalhando, e também auxiliarem completando o trabalho que se iniciou em sala de aula ou dentro da escola. } \\
\text { Para mim é importante a parceria família-escola. } \\
\text { A importância deles no caso, para mim, é justamente a mesma que eu atribuiria para qualquer outro participante } \\
\text { desse processo de ensino que o aluno recebe dentro da escola. A partir do momento que eu tenho um sujeito que tem } \\
\text { responsabilidade política, legal e emocional frente aos estudantes, ele tem relevância para mim, justamente porque é } \\
\text { uma comunidade em construção e reafirmação de conhecimento que a gente está formando ali dentro." } \\
\text { Acho que os pais são com certeza importantíssimos, por isso que quando eu converso com eles eu procurou pedir para } \\
\text { eles serem parceiros, vejo que professor e pais tem que haver parceria para que esse processo de ensino aprendizagem } \\
\text { possa fluir. } \\
\text { Os pais são muito importantes em todo o trabalho pedagógico que vai ser desenvolvido, por que até aquele pai que } \\
\text { muitas vezes a gente pensa em mandar certas tarefas, na dificuldade de estar auxiliando, mas aqueles pais estão ali } \\
\text { junto, você mostrar para eles que é importante acompanhar a criança na escola, que a criança se sente valorizada, } \\
\text { estimulada, é de fundamental importância o papel deles nesse trabalho que a gente faz. } \\
\text { Os pais são de suma importância, e os alunos eles sabem, eles têm consciência daqueles pais que são participativos, } \\
\text { daqueles que não. }\end{array}$ \\
\hline
\end{tabular}

Fonte: Dados da pesquisa.

Em 2012, Pereira (2013) iniciou um trabalho com os alunos sobre a importância do pai, em uma escola no bairro Bela Vista em São Paulo. Como, segundo ele, nunca havia realizado uma homenagem ao Dia dos Pais, não imagina que iria lidar com muitos depoimentos de revoltas, na relação dos alunos com os seus pais. Um desses relatos teve a seguinte fala de um aluno de 15 anos: "Odeio meu pai. Tenho vontade de matar ele porque nos abandonou e nunca me procurou". Esse trabalho relacionado ao assunto "pai" ocupou duas semanas, que antecederam o Dia dos Pais, no mês de agosto.

A dinâmica sistêmica, utilizada por Pereira (2013), foi trabalhar cada dia um detalhe sobre o relacionamento pai e filhos. Em um círculo de conversa foi proposto aos alunos que fechassem os olhos e, silenciosamente, pensassem nas respostas que seus corações estavam dando: "Ter raiva do pai ajuda você em alguma coisa? Faz você mais feliz? " "Às vezes, a mãe tem mágoa do pai, só que você como filho ou filha, não precisa sentir o mesmo que sua mãe." Vários outros questionamentos foram realizados nesse sentido.

No mês de setembro foi realizada uma reunião de pais, em que o autor relata que foi feita uma sondagem com as mães a respeito do que tinham achado do trabalho que havia desenvolvido junto com os filhos. Para ele foi uma conversa muito interessante, mostrando a importância dos pais na vida dos filhos, e quanto a alienação parental poderia ser prejudicial a formação psicológica do filho. Muitas mães deram sinal de entendimento desse erro de comportamento, e o quanto poderiam estar desenvolvendo um sentimento ruim e desnecessário nos filhos (PEREIRA, 2013).

Diante de um mundo em transformação, o sistema escolar, que se encontra entre a família e a sociedade, precisa construir outros olhares e escutas para atender a essa demanda, por meio de um novo paradigma educacional a exemplo da Pedagogia Sistêmica (CANSANÇÃO, 2013).

Essa mesma abordagem vem chegando devagar, como uma semente nas escolas do DF e o professor é o responsável por cultivar, em sua sala de aula, essa semente, para que essa possa germinar. A professora Hellen Vieira, coordenadora de professores da Educação Especial em Taguatinga-DF, pedagoga, especialista em alfabetização para o estudante com Deficiência Intelectual, com pós-graduação em Inteligência Multifocal e Psicanálise e Mestra em Psicologia (FONSECA, 2018), em 2009, atuou com crianças do $4^{\circ}$ ano de uma escola pública no DF, que segundo a diretora da escola, estavam com muitos problemas de comportamento. Apesar da professora regente ser dedicada, não entendia o que acontecia, pois não conseguia manter o controle da sala.

A primeira postura sistêmica adotada pela professora Hellen Vieira, foi receber as crianças na porta da sala, pegar na mão de cada uma, olhar nos olhos e dizer "Seja bem-vindo... Eu recebo você, seu pai e sua mãe, vocês têm um lugar no meu coração". Ela relata que as crianças a olharam com os olhos arregalados e entraram na sala, em seguida, realizaram um círculo, no qual depois de todos incluídos, trabalharam com músicas relacionadas à mãe e ao pai, em que tiveram a oportunidade de falar da família, com quem moravam, o que os pais faziam e o que elas faziam quando não estavam na escola. As crianças ouviram da professora que eles eram "misturinha do papai e da mamãe", ou seja, metade papai e metade mamãe e que os pais, mesmo estando longe ou tendo morrido, estavam nelas através das suas células (FONSECA, 2013). As crianças precisam adquirir respeito por si mesmos, serem capazes de identificar seus pontos fortes e fragilidades, lidar com suas emoções e manter a saúde física e o equilíbrio emocional (BRASIL, 2017).

Nesse círculo foi realizada também a dinâmica do "Eu Vejo Você", na qual todos tiveram a oportunidade de olhar para seus colegas e dizerem: "Agora, eu vejo você! Você faz parte!" Uma frase tão simples, mas que ao escutá-la ressoa o respeito do outro. Você é visto com toda a sua história e sem resistência. Inicia aí um movimento de concordância e respeito pelo outro, abordando o desenvolvimento social do indivíduo, propondo posturas que devem ter em relação ao outro (FONSECA, 2013). Desenvolvendo a necessidade de ser solidário, de dialogar e de colaborar com todos, respeitando a diversidade social, econômica, política e cultural (BRASIL, 2017; FONSECA, 2013).

Ao final da aula, confeccionaram bonequinhos 
representando o pai, a mãe e o filho(a), eles pintaram e, depois, fizeram um mural em sala de aula. Os alunos orientados a honrar os pais pela vida que chegou por meio deles e que através deles receberam a capacidade vital e com essa a força para se desenvolverem em relação ao Mundo interno e externo. Assim, todas às vezes que precisassem, como por exemplo, nas avaliações ou em outros momentos de ansiedade e nervosismo, deveriam ir até a foto ou a imagem representativa dos pais e colocar suas mãos em cima imaginando-lhes bem pertinho, ganhando suas forças e apoio para a resolução dos problemas. A maioria relatou que após esse exercício se sentiam mais calmos (FONSECA, 2013).

As evidências neurocientíficas também podem ser usadas para explicar esta possibilidade: no livro $\mathrm{O}$ cérebro da criança (SIEGEL; BRYTON, 2018) se vê uma porção de exercícios que mostram que ao pensar sobre um tema a criança pode organizar suas emoções e diminuir raiva e ansiedade, integrando assim o que o livro chama metaforicamente de andar de cima (córtex pré-frontal) - tomada de decisões, com o andar de baixo - amígdala cerebral- responsável pelas emoções; situação que também acaba por integrar o lado direito (emocional) e esquerdo (racional) do cérebro.

$O$ resultado foi surpreendente para a autora que relata que outro dia, ao chegar na sala, várias crianças queriam falar com ela sobre seus sentimentos e questões familiares, suas inseguranças quanto as brigas dos pais, dos vícios dos pais, das saudades que sentiam pelos pais após serem abandonados, entre outras questões. Para a professora, as crianças tiveram a oportunidade de reconhecerem as forças dos seus destinos, com isso cada família ser respeitada do jeito que era. Foi olhado para o amor das crianças pelos seus pais, sem nenhum julgamento, ajudando cada criança a reconhecer a sua força e seguir em frente, olhando para sua realidade e se alegrando com ela. Depois disso, muitas mães passaram a participar das atividades sistêmicas.

Nessa escola, as experiências com os bonequinhos desenhados representando os pais continuam sendo vivenciadas, até o momento desse relato, em muitas salas de aula de educação infantil ao $5^{\circ}$ ano e sempre com lindos e bons efeitos, segundo a autora do artigo (FONSECA, 2013).

A Pedagogia Sistêmica leva em conta o que há oculto nos sistemas familiares e escolares que impedem a pessoa de crescer, por meio do olhar da constelação familiar sistêmica (GUEDES, 2012). Experiência parecida relata Fátima Mello, em seu livro Constelações Pedagógicas: segundo a abordagem sistêmica de Bert Hellinger, que como pedagoga e psicopedagoga, recebeu um aluno de 7 anos e que, no início do ano letivo, este apresentou um comportamento muito agressivo e ansioso em relação aos colegas de sala. A criança queria que a mãe permanecesse na escola com ela. A coordenação em uma conversa com a mãe, que relata que era viúva e que o menino não havia conhecido o pai, que havia falecido, quando ela ainda estava grávida dele. Relatou que seu filho havia mudado de comportamento, após saber que iria se casar novamente. Foram feitas diversas tentativas de atendimento ao aluno na abordagem tradicional, mas nada havia surtido efeito. A escola, então, solicitou uma consultoria com apoio de uma profissional da Pedagogia Sistêmica.

No primeiro atendimento ao aluno, a professora sistêmica iniciou dizendo como ele tinha um sorriso bonito e que deveria ser parecido com o do pai dele, e que por ele ser formado por $50 \%$ (cinquenta por cento) das células do pai e $50 \%$ (cinquenta por cento) das células da mãe, o seu pai estaria sempre em seu coração. Falou que eles estariam conectados por "um fio invisível do coração" e que se ele fechasse os olhos e colocasse a mãozinha no peito iria sentir o papai nas batidas do coração e que mesmo que sua mãe casasse de novo, o seu pai teria um lugar só dele em seu afeto. A professora solicitou a todos os alunos, que trouxessem fotos dos seus pais, e com as fotos montaram um grande mural. $\mathrm{O}$ menino mudou completamente o seu comportamento em casa e na escola. A inclusão do pai trouxe paz e equilíbrio que passou a permanecer na escola sem exigir a presença física da mãe (MELLO, 2018).

Este trabalho também se insere na perspectiva de Maturana e Verden-Zöller (2011) no clássico Amar e Brincar Fundamentos Esquecidos do Humano, que traz a dimensão humana para o ato do ensino formal. Igualmente, as rodas de conversa - que remetem aos anteriores círculos de cultura de Freire (1987) já citados - são colocadas neste mesmo intuito, nas palavras de Pacheco, Eggertsdóttir e Marinósson (2006), o primeiro é o co-criador da Escola da Ponte em Portugal, ao dizer que se pode salvar vidas nas escolas com esta simples e breve prática cotidiana, diminuindo bullying e automutilação, crescentes em números alarmantes pelo Mundo afora ${ }^{6}$ ao se olhar uns para os outros: "você existe para mim, eu te vejo!"

Pessoa (2015), preocupada com o contexto da exclusão escolar, teve sua experiência quando, em 2004, realizou um trabalho com o tema inclusão, ou ordem do pertencimento de Hellinger (2003), em uma escola de Mogi das Cruzes. Era uma aluna que estava mudando de sala e por sentir resistência do outro grupo em aceitá-la, estava pensando em sair da escola. A professora fez a interferência com o exercício: "Você é uma de nós", em que os alunos ficaram posicionados lado a lado na entrada da sala e a aluna, que se sentia excluída, foi entrando e passando por cada um que repetia a frase: "Você é uma de nós" e a garota respondia: "Sim, eu sou uma de vocês". Heloisa Pessoa relata que foi um dos primeiros exercícios e considerou que foi importante ter feito dessa maneira, pois posteriormente os alunos vinham relatar dificuldades em relação à aproximação de outros grupos de outras salas e, assim, foram fazendo as inclusões de todos com respeito a cada um (PESSOA, 2015).

Garlet (2015), como professora dos anos finais do 
Ensino Fundamental, em uma escola pública municipal em Uberlândia/MG, com a permissão da direção da escola, no ano de 2007, colocou em prática os exercícios sistêmicos de acordo com a Pedagogia Sistêmica. Desde o primeiro dia de aula, ela convidou os alunos a conhecerem o trabalho, explicando a importância de se respeitar os pais e o próprio destino. Iniciou formando um círculo no qual todos se abraçaram desejando boas-vindas ao novo ano letivo. Em seguida, sugeriu que se imaginassem em contato com os pais: se encostassem, ficassem no colo, como bebês e sentissem o conforto de estarem protegidos por eles, mesmo não tendo conhecido um deles ou ambos e agradecessem a vida. À medida que fazia isso, periodicamente, foi observando que muitos alunos não conseguiam se encostar nos próprios pais, então durante o exercício ia até a carteira da criança e imaginava os pais atrás do aluno, fazendo uma reverência de respeito e gratidão.

A mesma professora Garlet (2015) relata que passou a presenciar resultados satisfatórios como alunos mais concentrados, realização de tarefas por muitos que não faziam, menos rebeldia e grandes aprovações ao final do ano letivo. O foco da Pedagogia Sistêmica está no melhoramento de toda a turma de forma colaborativa. Para isso, os alunos se ajudam mutuamente, complementando talentos e habilidades específicas, se empoderando com competências que os auxiliem a serem protagonistas de mudanças significativas na sociedade e na formação de alunos aptos à criação de seu próprio futuro (BRASIL, 2017).

A respeito disso se sugere a leitura acerca da evolução da família, a partir da mudança nas histórias infantis, em uma analogia interessante que se pauta nas mudanças da proposição da guarda compartilhada - desde sua proposição legal como exceção, em 2008, para regra na condução legal das decisões sobre os filhos em caso de separação conjugal em 2014 - (FERNANDES et al, 2018). O referido estudo mostra a família sob a tutela exclusiva do pai como em Procurando Nemo e as novas tarefas assumidas por este, como em Os Incríveis e Moana ${ }^{7}$.

O que se espera com as posturas sistêmicas dos educadores é que eles se sintam bem dentro da turma. Nessa visão, o professor assume uma postura de estar ao lado dos alunos para olharem os objetivos juntos, criando espaços de formação transformadora (FRANKE-GRICKSCH, 2016; PACHECO, 2014). Para Franke-Gricksch (2016), se o grupo está bem nesse sentido, aprender cálculo e outras coisas será muito mais fácil; e ao se acrescentar sem descargas desnecessárias de cortisol e adrenalina típicos do estresse crônico, que inibem a aprendizagem - conseguida somente com prazer e motivação.

\section{Conclusão}

O futuro educacional mundial precisa de renovações, sendo preciso repensar e refazer as atitudes, isto é, novos tempos pedem novas práticas.

Nesta pesquisa se observa um novo paradigma educacional que leva a repensar a realidade, a partir de uma visão de sistemas em conexão: famílias, escolas, professores, diversos agentes educacionais e os contextos sócio-históricos de cada um dos envolvidos.

Para a Pedagogia Sistêmica, a família confia nas escolas o bem maior que possuem, que são seus filhos, e o respeito ou o não respeito do professor a esta família será capaz de estimular ou bloquear o desenvolvimento e a capacidade de aprendizagem do estudante, sobretudo da criança.

Não se pode esquecer também dos ganhos afetivos e efetivos do professor nesta abordagem, haja vista que ele próprio estará olhando oportunamente junto com seus alunos para suas questões emocionais; os dilemas com a saúde ocupacional geram a necessidade emergente de um espaço de escuta, gerenciamento e administração do estresse oriundo deste labor, diante da urgência de maior atenção nos prejuízos da atividade docente àquele que a exerce: o professor.

Com os resultados obtidos com as atividades sistêmicas, aplicadas pelos professores citados neste estudo, foi possível observar e sentir a importância de olhar para o outro com toda a sua história de vida e dizer sim com todo o respeito, isentos do olhar julgador e cheio de cobranças de quando se analisam as situações sob o único ponto de vista, quando então se poderá realizar a verdadeira inclusão escolar.

Essa mudança de postura leva a uma reflexão de que se recebe em sala de aula não somente a criança, mas também seus sonhos, seus ideais, seus medos e anseios e, às vezes, esses espaços são lugares de esperança de um futuro melhor para todos que fazem parte desse sistema. Uma escola que não olha com respeito para os pais e mães dos seus alunos arrisca perder um conhecimento de enorme valor para estimular o êxito dos estudantes.

A Pedagogia Sistêmica surge, neste cenário, como um novo paradigma educacional, com uma nova forma de olhar que implica trocas profundas na forma de pensar a educação e para todos aqueles que influenciam no ato educativo que são as famílias, os alunos e todo a comunidade escolar.

\section{Referências}

ANDRADE, F.S.B. Qual o lugar do papai? Percepções e práticas de Educação Sistêmica para educadores, psicopedagogos e terapeutas. Brasília: Editar, 2018.

BRASIL. Ministério da Educação. Base Nacional Comum Curricular. Educação é a Base. Brasília: MEC, 2017.

\footnotetext{
7 Este artigo apresenta um resgate histórico da família e da infância, situando as modificações em sua estruturação ao longo do tempo, partindo da Antiguidade até o século XX; e apresenta a lei da Guarda Compartilhada como fruto das configurações familiares da atualidade, que traduz a mudança histórico-social na constituição da família (Lei nº 11.698/08 alterada, em 2014, pela Lei n ${ }^{\circ}$ 13.058, quando nesta última a modalidade passa a ser regra e não exceção).
} 
BRASIL. Ministério da Educação. Estudo de abrangência nacional sobre a saúde dos professores é realizado pelo MEC e UFMG. (2016). Disponível em: http://pne.mec.gov.br/maisdestaques/545-estudo-de-abrangencia-nacional-sobre-a-saudedos-professores-e-realizada-pelo-mec-e-ufmg. Acesso em: 20 abr. 2020 .

CANSANÇÃO. E.C. Construindo pontes entre a família e a escola. Informativo Psicopedagógico, GESPpMA, 2013.

CELESTINO, A.S. Concepções sobre dificuldades de aprendizagem. 2013. Disponível em: <https://www.atribunamt. com.br/2013/10/31/concepcoes-sobre-dificuldades-deaprendizagem/> Acesso em: 26 jan. 2020.

CORTELLA, M.S. Educação, escola e docência: novos tempos, novas atitudes. São Paulo: Cortez, 2014.

CURY. A. 20 regras de ouro para educar filhos e aluno: como formar mentes brilhantes na era da ansiedade. São Paulo: Planeta, 2017.

FERNANDES, C.T. et al. Família e infância no passado e no presente: considerações sobre a guarda compartilhada. Rev. Mundi Soc. Hum., v.3, n.3, 37-65, 2018.

FONSECA, H.V. As aventuras da professora Tina: o coração e o fio invisível. Percepções e Práticas de Educação Sistêmica para Educadores, Psicopedagogos, Terapeutas e Pais. Brasília: Editar, 2018.

FONSECA, H.V. Pedagogia Sistêmica: uma semente para o futuro do Brasil. Conexão Sistêmica Sul, v. 3. p 76, 2013.

FRANKE-GRICKSCH, M. Você é um de nós: percepções e soluções sistêmicas para professores, pais e alunos. Patos de Minas: Atman, 2009.

FRANKE-GRICKSCH, M. O benefício da Pedagogia Sistêmica na Educação. Conexão Sistêmica Sul, v.3.p-85-88, 2013.

FRANKE-GRICKSCH, M. Modelo sistêmico para educadores. Rev. Eu Estudante, 2016. Disponível em: https:// www.Correiobraziliense.com.br /app/noticia/ eu-estudante/ ensinoeducacaobasica/interna-educacaobasica-2019,

560731/modelo-sistemico-para- educadores.shtml . Acesso em: 21 abr. 2020.

FRAZÃO, A. O que é a Síndrome de burnout e como evitar. Tua Saúde, 2018. Disponível em: https://www.tuasaude.com/ sindrome-de-burnout/". Acesso em: 10 abr. 2020.

FREIRE, P. Pedagogia do oprimido. Rio de Janeiro: Paz e Terra, 1987.

GARCIA, A.P.O. Pedagogia Hellinger. São Paulo: Terrahumida, 2019.

GARLET, A. Pedagogia sistêmica: relatos de uma professora de Ensino Fundamental com as Constelações Familiares. 2015. Disponível em https://iperoxo.com/2015/07/01/pedagogiasistemica-relatos-de-uma-professora-de-ensino-fundamentalcom-as-constelacoes-familiares. Acesso em: 20 abr. 2020.

GOMES, R.M.S.; PEREIRA, A.M.S. Estratégias de coping em educadores de infância portugueses. Psicol. Esc. Educ., v.12, n.2, p.319-326, 2008.

GUEDES, O. Pedagogia Sistêmica: O que traz quem levamos para a escola? Curitiba: Appris, 2012.

HECKERT, A.L. et al. A dimensão coletiva da saúde: uma análise das articulações entre gestão administrativa e saúde dos docentes, a experiência de Vitória. In: ATHAYDE, M.E.; BARROS, J.; BRITO; M.Y. Trabalhar na escola? Só inventando o prazer. Rio de Janeiro: Edições IPUB/CUCA, 2001. p.123-162.
HELLINGER, B.; HOVEL, G.T. Constelações familiares: o reconhecimento das ordens do amor. São Paulo: Cultrix, 2001.

HELLINGER, B. Ordens do amor: um guia para o trabalho com constelações familiares. São Paulo: Cultrix, 2003.

HELLINGER, B. Bert Hellinger: meu trabalho, minha vida. São Paulo: Cultrix, 2020

JENNINGS, P.A. et al. Impacts of the CARE for teachers program on teachers' social and emotional competence and classroom interactions. 2018. Disponível em: https://createforeducation. org/care/care-research/. Acesso em: abr. 302020.

KABAT-ZINN, J. Wherever you go, there you are. New York: Hachette Books, 2005.

MERLEAU-PONTY, M. Fenomenologia da percepção. São Paulo: Martins Fontes, 1999.

MATURANA, H.; VERDEN-ZÖLLER, G. Amar e brincar: fundamentosesquecidos dohumano. SãoPaulo:PalasAthena, 2011.

MELLO, F. Constelações pedagógicas: segundo a abordagem sistêmica de Bert Hellinger. São Paulo: Leader, 2018.

OPAS $\backslash$ OMS. Plano de Ação sobre a saúde dos trabalhadores. 2015-2025. 2015. Disponível em:https://iris.paho.org/ bitstream/handle/10665.2/33985/CD54_10Rev.1-por. pdf? sequence=1\&isAllowed=y Acesso em: 30 abr. 2020 .

PACHECO. J. Escola da ponte: formação e transformação da educação. Petrópolis: Vozes, 2014.

PACHECO, J.; EGGERTSDÓTTIR, R.; MARINÓSSON, G.L. Caminhos para a inclusão: um guia para aprimoramento da equipe docente. Porto Alegre: Atmed, 2006.

PEREIRA. C.G. O pai, muitas vezes, incompreendido. Conexão Sistêmica Sul, v.3, p.78-79, 2013.

PESSOA, H. Uma experiência com a Educação Sistêmica. Conexão Sistêmica, v.2, p.101-105, 2015.

PIOLLI, E.; HELOANI, J.R.M.; SILVA, E.P. Sofrimento e heteronomia: reflexões sobre as políticas de (pseudo) valorização do trabalho do diretor da escola. Comunicações, v.20, n.2, p.117-132, 2013.

ROSEMBERG, M. A linguagem da paz em um mundo de conflitos. São Paulo: Palas Athena, 2019.

ROSS, R.; ALTMAIER, E. Intervention in occupational stress. London: Thousand Oaks \& New Delhi, Sage Publications, 1994.

SHELDRAKE, R. A presença do passado: ressonância mórfica. Lisboa: Instituto Piaget, 1996.

SHELDRAKE. R. A sensação de estar sendo observado. São Paulo: Cultrix, 2004.

SIEGEL, D. J; BRYSON, T.P. O cérebro da criança: 12 estratégias revolucionárias para nutrir a mente em desenvolvimento do seu filho e ajudar sua família a prosperar. São Paulo: NVersos, 2018.

CUDEC - Universidade Multicultural. 2019. Disponível em: $<$ Chttp://www.universidadcudec.com/cursos/maestria-enpedagogia-sistemica/>. Acesso em: 15 abr. 2020.

VIEIRA, J.L.T. Introdução a pedagogia sistêmica: uma nova postura para pais e educadores. Campo Grande: Ed. Life, 2018.

VIEIRA, M.D.C.; SIVEK, C.S; CAVALCANTE, M.M.D. Pedagogia Sistêmica: contexto e fundamentos. Rev. Expressão Católica, v.4, n.1, p.113-121, 2014.

ZURLO, M.C.; PES, D.; COOPER, C.L. Stress in teaching: a study of occupational stress and its determinants among Italian school teachers. Stress Health, v.23, p.231-241, 2007. 